\title{
Ending Neglected Surgical Diseases (NSDs): Definitions, Strategies, and Goals for the Next Decade
}

\author{
Jaymie A. Henry ${ }^{1,2,3^{*}}{ }^{\mathbb{D}}$, Angela S. Volk ${ }^{4}$, Sicily K. Kariuki ${ }^{5}$, Kiraitu Murungi ${ }^{6}$, Trina Firmalo ${ }^{7}$, Ruth Laibon \\ Masha $^{8}$, Orion Henry ${ }^{9}$, Peter Arimi ${ }^{10}$, Patrick Mwai ${ }^{2}$, Estella Waiguru ${ }^{5}$, Evans Mwiti ${ }^{11}$, Dan Okoro ${ }^{12}$, Angella \\ Langat $^{13}$, Cosmas Mugambi ${ }^{5}$, Erin Anastasi ${ }^{14}$, Gillian Slinger ${ }^{15}$, Chris Lavy ${ }^{16,17}$, Rosalind Owen ${ }^{17}$, Erin \\ Stieber $^{18}$, Marc Lester Suntay ${ }^{19}$, Danny Haddad ${ }^{20}$, Robert Lane ${ }^{21}$, Joel Buenaventura ${ }^{22}$, Neil Parsan ${ }^{23}$, Fizan \\ Abdullah $^{24}$, Michael Nebeker ${ }^{25}$, Lismore Nebeker ${ }^{25}$, Charles Mock $^{26}$, Larry Hollier ${ }^{4}$, Pankaj Jani ${ }^{27}$
}

\begin{abstract}
While there has been overall progress in addressing the lack of access to surgical care worldwide, untreated surgical conditions in developing countries remain an underprioritized issue. Significant backlogs of advanced surgical disease called neglected surgical diseases (NSDs) result from massive disparities in access to quality surgical care. We aim to discuss a framework for a public health rights-based initiative designed to prevent and eliminate the backlog of NSDs in developing countries. We defined NSDs and set forth six criteria that focused on the applicability and practicality of implementing a program designed to eradicate the backlog of six target NSDs from the list of 44 Disease Control Priorities 3rd edition (DCP3) surgical interventions. The human rights-based approach (HRBA) was used to clarify NSDs role within global health. Literature reviews were conducted to ascertain the global disease burden, estimated global backlog, average cost per treatment, disability-adjusted life-years (DALYs) averted from the treatment, return on investment, and potential gain and economic impact of the NSDs identified. Six index NSDs were identified, including neglected cleft lips and palate, clubfoot, cataracts, hernias and hydroceles, injuries, and obstetric fistula. Global definitions were proposed as a starting point towards the prevention and elimination of the backlog of NSDs. Defining a subset of neglected surgical conditions that illustrates society's role and responsibility in addressing them provides a framework through the HRBA lens for its eventual eradication.

Keywords: Neglected Surgical Diseases, NSD, Neglected Surgical Conditions, Untreated Surgical Conditions, Essential Surgery, Global Surgery

Copyright: (c) 2022 The Author(s); Published by Kerman University of Medical Sciences. This is an open-access article distributed under the terms of the Creative Commons Attribution License (https://creativecommons.org/licenses/ by/4.0), which permits unrestricted use, distribution, and reproduction in any medium, provided the original work is properly cited.

Citation: Henry JA, Volk AS, Kariuki SK, et al. Ending neglected surgical diseases (NSDs): definitions, strategies, and goals for the next decade. Int J Health Policy Manag. 2022;11(9):1608-1615. doi:10.34172/ijhpm.2020.140
\end{abstract}

\section{Article History: \\ Received: 7 January 2020 Accepted: 19 July 2020}

ePublished: 11 August 2020

\section{Introduction}

Despite steady gains in raising the profile of surgery in public health, untreated surgical conditions continue to plague certain societies, causing $25 \%$ of avoidable mortality ${ }^{1}$ and up to $40 \%$ of avoidable morbidity ${ }^{2,3}$ in low- and middleincome countries (LMICs). Unaddressed, these conditions progress to profound disability, deformity, or early death due to a lack of timely access to essential surgical care. These conditions, highlighted by the World Bank's Disease Control Priorities 3rd edition (DCP3) on Essential Surgery, ${ }^{4}$ remain the poster children of surgical neglect. Previous articles have called for greater attention to these conditions, ${ }^{5-8}$ yet no current global strategy exists to systematically end the neglect. In this perspective, we will expound and discuss the concept of 'neglected surgical diseases', or NSDs. We define NSDs as "any treatable surgical condition that has progressed beyond functional repair due to a lack of access to timely surgical care." NSDs disproportionately impact citizens of LMICs, resulting in an enormous burden on society with lost economic productivity, social stigma, and immense suffering. Implementing safe and cost-effective interventions, ${ }^{9}$ treatment could avert an estimated 17 million deaths and over 77 million disability-adjusted life-years (DALYs) annually. ${ }^{4}$ However, due to stigma, lack of awareness, lack of access, political will, and financial support, these conditions are not systematically addressed in most public health programs or treated in primary care or community settings.

An additional 143 million surgical procedures are required each year to meet the need in LMICs. ${ }^{10}$ Of those receiving surgery, high perioperative mortality and complication rates are seen. ${ }^{11}$ A review of National Health Strategic Plans in 43 sub-Saharan African countries revealed a lack of surgical prioritization: $19 \%$ had no mention of surgery and only $47 \%$ referenced traumatic conditions despite high injury mortality rates in those regions. ${ }^{12}$ Most NSDs are not included in national censuses or are underestimated in global health databases. In the worst affected countries, the political language for 'Global Surgery' has yet to be written. ${ }^{13-16}$ Yet an 
average of USD 573 million in aid are spent yearly on surgical conditions, mostly from non-governmental organizations (NGOs) run by high-income countries, signifying not only backlogs in underdeveloped regions, ${ }^{11}$ but also funding interest from the global health community. ${ }^{17}$ The question we now face is how to leverage these resources and build systems of care that are integrated, sustainable, dignified, inclusive, and more importantly, local, in order to leave a legacy of surgical capacity building in the most remote areas of need.

As the world looks to achieve the Sustainable Development Goals by 2030 with a grand, but attainable vision for universal health coverage (UHC): 'Leaving No One Behind;' strategies to improve surgical access, availability, and safety for the bottom billion are paramount. Global progress has been achieved in advancing surgical care with the World Health Organization (WHO) resolution on Essential Surgery, ${ }^{18}$ the landmark publication of the Lancet Commission on Global Surgery $(\mathrm{LCoGS})^{10}$, and current work on national surgical plans ${ }^{19,20}$; additional gains can be achieved with addressing NSDs complementing these efforts through a systematic approach that unifies the intersection of human rights, public health, and Global Surgery. We therefore aim to: (1) discuss an approach for classifying six NSDs from a human rights-based perspective, (2) propose a global definition of the neglect, and (3) propose a public health strategy for addressing these conditions at a global level.

\section{A Human Rights-Based Approach}

Health inequities are avoidable differences in health between population groups caused by socioeconomic conditions. ${ }^{21}$ The recent LCoGS report estimated that only $6 \%$ of all surgical procedures done worldwide occur in the poorest nations where a third of the global population reside, ${ }^{10}$ highlighting a massive issue of surgical inequity. Global backlogs, therefore, exist due to this disparity. Traditional frameworks have been proposed for addressing health inequities in general, which incorporate a patient-centered design including families and communities, data analytics, and continuous improvement. ${ }^{22}$ A human rights-based approach (HRBA) does not 'simply describe the situation in terms of human needs, but also incorporates society's obligation to respond to the inalienable rights of individuals and empowers people to demand justice as a right. ${ }^{23}$ Thus, addressing NSDs with this approach clarifies its role within the global health milieu. ${ }^{24}$ The following HRBA principles were applied to clarifying the role of NSD in global health. In brief, universality of protection ensures that marginalized surgical patients should be included as part of primary care or UHC programs insofar as being able to utilize public resources to aid in screening, detection, reporting, treatment, and to offer financial protection when needed. Institutionalizing surgery within public health addresses HRBA's principles of having comprehensive, coherent and coordinated policies for neglected surgical patients with adequate legal and institutional frameworks, long-term social protection strategies, standards of accessibility, adaptability and acceptability, and adequacy of benefits such as timely access to care. The principle of dignity, autonomy, equality and non-discrimination protects surgical patients' right to public policies and services that reach the most marginalized. Gender perspective highlights surgery's indispensable role in mitigating women's morbidity and mortality from a lack of access to emergency obstetric surgical services. Formal involvement of local government agencies with active civil society participation in programs that address surgical inequities address the principles of access to accountability mechanisms and effective remedies. Community involvement in the prevention and detection of surgical conditions ensure meaningful and effective participation.

For purposes of defining NSDs, a usable set of index surgical conditions for a target surgical population was generated from the DCP3 list of 44 surgical interventions using six criteria to address the applicability and practicality of implementing the NSD program focusing on key conditions:

- Impact. A candidate disease has an avertable high lifetime DALY burden.

- Cost-effectiveness. The cost of performing the surgery in a low-resource setting is much lower than the societal cost of DALYs carried by a disabled person.

- Feasibility. The surgical intervention can be done in a lowresource setting and do not require advanced equipment to be done safely.

- Quality and safety. The candidate disease is not an emergency, allowing a local government unit (LGU) district and/or referral hospital or its equivalent to ensure that they can deliver quality safe surgery before having to handle the complexities of safe emergency services.

- Relevance. The candidate disease forms part of a group of conditions that confer a significant burden of morbidity and mortality in a population of neglected patients large enough to ensure that local or specially designated providers can be trained and/or supported fully in the LGU district and/or referral hospital working on their local population.

- Public health significance. The candidate disease can be prevented or the backlog of neglected, advanced cases can be eradicated through early detection and management.

Criteria 1 and 2 disarm the argument that surgical care is too expensive, whereas NSDs, by definition, are too expensive not to treat. ${ }^{9}$ Criteria 3, 4, and 5 ensure that any LGU district and/or referral hospital can cost-effectively and easily upgrade their current facilities and train their current staff to deal with NSDs. Criterion 5 ensures that adequate training can be done on site at the LGU district and/or referral hospital, thus addressing concerns of "brain drain" and the difficulties of relocating surgeons to work in remote rural hospitals. These criteria emphasize a 'whole of system' approach in the prevention and elimination of NSDs, bringing the treatment close to the people as most of them are found in remote and under resourced communities.

Based on these criteria, all emergent or time-dependent conditions and preventive surgical interventions were excluded as well as two other conditions that did not meet the definition of an NSD and $>50 \%$ of the NSD criteria (excision of common benign tumors and repair of anorectal malformation and Hirschsprung's disease). Six NSDs were therefore identified (Table 1) and discussed with proposed 
global definitions to establish uniformity and markers of progress (Table 2). The global disease burden, estimated global backlog, average cost per treatment, DALYs averted from the treatment, information on return on investment, and potential gain and economic impact from literature reviews are presented in Table 3.

Disease Eradication: The Holy Grail of Public Health Unlike infectious diseases where eradication of a disease entity entails total abolition of a pathogen and its concomitant transmission pathways, surgical disease elimination confers a different mindset as surgical conditions arise from various etiologies - whether it be genetic, iatrogenic, functional, or environmental - and will arise regardless of the circumstance. What can be eliminated, however, are advanced forms of surgical disease that fundamentally incapacitates an individual and prevents that human being from living a humane and productive life as can be reasonably expected by society. This will entail ensuring the availability of timely access to surgical care which can be measured from a population perspective by: (a) surgical repair commensurate with the endemic incidence rate, and (b) for congenital deformities, less than $5 \%$ of newly identified cases at or below the recommended age of repair.

The elimination strategy for each NSD will vary slightly per

Table 1. DCP3 Essential Surgery List of 44 Surgical Interventions That Meet the Predefined NSD Criteria

\begin{tabular}{|c|c|c|c|c|c|c|}
\hline DCP3 Non-urgent Conditions & Impact & $\begin{array}{c}\text { Cost- } \\
\text { Effectiveness }\end{array}$ & Feasibility & $\begin{array}{c}\text { Quality and } \\
\text { Safety }\end{array}$ & Relevance & $\begin{array}{l}\text { Public Health } \\
\text { Significance }\end{array}$ \\
\hline Fracture reduction (malunion) & $x$ & $x$ & $x$ & $x$ & $x$ & $x$ \\
\hline Hydrocelectomy & $x$ & $x$ & $x$ & $x$ & $x$ & $x$ \\
\hline Elective hernia repair & $x$ & $x$ & $x$ & $x$ & $x$ & $x$ \\
\hline Excision of common benign tumors & $-a^{a}$ & $-{ }^{a}$ & $x$ & $x$ & $-{ }^{a}$ & $x$ \\
\hline Cataract extraction and insertion of intraocular lens & $x$ & $x$ & $x$ & $x$ & $x$ & $x$ \\
\hline Eyelid surgery for trachoma & $x$ & $x$ & $x$ & $\mathrm{x}$ & $\mathrm{x}$ & $x$ \\
\hline Repair obstetric fistula & $\mathrm{x}$ & $\mathrm{x}$ & $\mathrm{x}$ & $x$ & $x$ & $x$ \\
\hline Repair of cleft lip and palate & $\mathrm{x}$ & $\mathrm{x}$ & $\mathrm{x}$ & $x$ & $x$ & $\mathrm{x}$ \\
\hline Repair of anorectal malformations and Hirschsprung's disease & $x$ & $-\mathrm{b}$ & $-c$ & $-d$ & $-\mathrm{e}$ & $x$ \\
\hline
\end{tabular}

Abbreviations: DCP3, Disease Control Priorities 3rd edition; NSD, neglected surgical disease.

All emergent procedures excluded, a- variable, depends on location and size of tumor, prevalence difficult to determine due to heterogeneous nature of disease burden, b- will need more resources to treat, c- will need specially trained providers, $d$ - emergency decompression needed at birth, e- relative numbers not large enough.

Table 2. Proposed Global Definition for Index NSDs

\begin{tabular}{|c|c|}
\hline NSDs & Proposed Global Definition \\
\hline $\begin{array}{l}\text { Neglected cleft lip and/or } \\
\text { palate }\end{array}$ & $\begin{array}{l}\text { i. } \quad \text { Cases of unrepaired CLP beyond } 6 \text { (lip) and } 18 \text { (palate) months of age } 25 \\
\text { ii. Surgical repair occurring below the disease incidence rate } \\
\text { iii. Lack of systems and comprehensive cleft care teams to identify and properly manage cleft disease using defined } \\
\text { strategies, with appropriately available financial resources }\end{array}$ \\
\hline Neglected clubfoot & $\begin{array}{l}\text { i. } \\
\text { ii. } \\
\text { iii. } \\
\text { initiation of treatment at a rate below the reported incidence in LMICs } \\
\text { appropriately available financial resources }\end{array}$ \\
\hline $\begin{array}{l}\text { Neglected avoidable } \\
\text { blindness }\end{array}$ & $\begin{array}{l}\text { i. Blindness caused by any preventable disease, especially unrepaired cataracts and trachoma } \\
\text { ii. Initiation of treatment at a rate below the reported incidence in LMICs } \\
\text { iii. Lack of access to proper surgical care, including a trained ophthalmic surgical provider, proper equipment and } \\
\text { infrastructure, supporting teams, and available financial resources }\end{array}$ \\
\hline Neglected obstetric fistula & $\begin{array}{l}\text { i. Cases of unrepaired obstetric fistula for more than one year } \\
\text { ii. Lack of systems and enablers (both supply and demand-side) to ensure timely, quality care to identify and properly } \\
\text { manage and prevent women from developing an obstetric fistula }\end{array}$ \\
\hline $\begin{array}{l}\text { Neglected hernia and/or } \\
\text { hydrocele }\end{array}$ & $\begin{array}{l}\text { i. Any unrepaired symptomatic or advanced groin hernia and/or hydrocele in LMIC populations } \\
\text { ii. Lack of systems and care teams to identify hernia and/or hydrocele presence with appropriately available } \\
\text { infrastructures and financial resources to perform surgical repair }\end{array}$ \\
\hline
\end{tabular}

Abbreviations: CLP, cleft lip and/or palate; NSD, neglected surgical disease; LMIC, low- and middle-income country. 
Table 3. NSD Estimated Global Prevalence, Incidence, Backlog, Cost of Treatment, DALY Averted, ROI, and Economic Impact of Treatment

\begin{tabular}{|c|c|c|c|c|c|c|}
\hline & CLP & Clubfoot & Cataracts & Injuries & Hernia & Fistula \\
\hline $\begin{array}{l}2017 \mathrm{GBD}^{15} \\
\text { prevalence } \\
\text { (thousands) }\end{array}$ & $\begin{array}{l}10816.4 \text { (9945.7 to } \\
11654.1)\end{array}$ & $\begin{array}{l}16262.8 \text { (14 } 519.3 \text { to } 18611.7 \text { ) } \\
\text { (other congenital musculo- } \\
\text { skeletal anomalies) }\end{array}$ & $\begin{array}{l}107987.7 \text { (95 } 775.3 \text { to } \\
122319.3 \text { ) }\end{array}$ & $\begin{array}{l}1507481.4(1439758.0 \text { to } \\
1587209.4)\end{array}$ & $\begin{array}{l}26490.8 \text { ( } 24196.8 \text { to } 28760.4 \text { ) } \\
\text { (inguinal, femoral, and abdominal } \\
\text { hernia) } \\
\text { LF: } 64623.4 \text { (59 } 178.2 \text { to } 70866.1 \text { ) }\end{array}$ & $\begin{array}{l}1127.5 \text { (939.1 to } 1338.2 \text { ) } \\
\text { (maternal obstructed labour complications) }\end{array}$ \\
\hline $\begin{array}{l}2017 \mathrm{GBD}^{15} \\
\text { incidence } \\
\text { (thousands) }\end{array}$ & $\begin{array}{l}195.5 \text { (152.0 to } \\
249.3)\end{array}$ & $\begin{array}{l}929.0 \text { ( } 801.7 \text { to } 1074.0 \text { ) (other } \\
\text { congenital musculo-skeletal } \\
\text { anomalies) }\end{array}$ & $--^{-a}$ & 520710.3 (493 430.2 to 547988.6 ) & $\begin{array}{l}41182.8 \text { ( } 36372.8 \text { to } 46265.0 \text { ), } \\
\text { (inguinal, femoral, and abdominal } \\
\text { hernia) } \\
293 \text { per } 100000 \text { population }\end{array}$ & $\begin{array}{l}220.7 \text { ( } 179.2 \text { to } 267.7) \text {, (maternal obstructed } \\
\text { labour complications) } \\
50000 \text { to } 100000 \text { worldwide develop a fistula } \\
\text { annually27,28; } 60000 \text { to } 90000 \text { annually in SSA } \\
\text { alone }^{27}\end{array}$ \\
\hline $\begin{array}{l}\text { Estimated global } \\
\text { backlog (or } \\
\text { unmet need) }\end{array}$ & $\begin{array}{l}400000 \text { and } 2 \\
\text { million globally } \\
\text { Burden in LMIC } \\
\text { (2014): } 5000 \\
\text { deaths, } 1000000 \\
\text { DALYS }^{27}\end{array}$ & $\begin{array}{l}1 \text { million (GCI) } \\
72 \% \text { of children going } \\
\text { untreated each year }{ }^{30}\end{array}$ & $\begin{array}{l}20 \mathrm{M}(2010)^{31} \\
\text { Blindness: } 12.6 \mathrm{M}^{32} \\
\text { Blindness and MSVI: } 65.2 \mathrm{M}^{32,33}\end{array}$ & $\begin{array}{l}\text { Burden in LMIC (2014): } \\
\text { RTI: } 1160000 \text { deaths; } 72000000 \\
\text { DALYS } \\
\text { Other unintentional injuries: } \\
1550000 \text { deaths; } 96000000 \\
\text { DALYS } \\
\text { Intentional injuries: } 540000 \text { deaths, } \\
34000000 \text { DALYS }^{27}\end{array}$ & $\begin{array}{l}163-357 \text { per } 100000 \text { population per } \\
\text { year for all cases } \text { cas }^{27}\end{array}$ & Approximately 500000 existing cases* \\
\hline $\begin{array}{l}\text { Average cost per } \\
\text { treatment }\end{array}$ & $\begin{array}{l}\text { US\$250 per child } \\
\text { US\$10-110 per DALY } \\
\text { averted }^{27} \\
\text { Specialized cleft } \\
\text { clinic in India: } \\
\text { US\$300 per DALY } \\
\text { averted }^{34}\end{array}$ & $\begin{array}{l}\text { US\$140-161 per child } 35,36 \\
\text { Cost per child will decrease } \\
\text { over time from } \$ 317 \text { in } 2017 \text { to } \\
\$ 82 \text { in } 2030\end{array}$ & $\begin{array}{l}\text { Short-term cataract hospitals } \\
\text { US\$50 vs. NGO hospitals of } \$ 46 \\
\text { per case } \mathrm{e}^{27} \\
\text { US\$50 per DALY averted }{ }^{27}\end{array}$ & $\begin{array}{l}\text { District trauma: } \$ 77-223 / \text { DALY } \\
\text { averted } \\
\text { Improving first aid skills of lay first } \\
\text { responders }<\$ 10 \text { per year of life } \\
\text { gained }{ }^{27} \\
\text { Burn care: average daily cost per } \\
\text { patient US\$6; average overall cost } \\
\text { for burn admission US\$62 }\end{array}$ & $\begin{array}{l}\text { Ecuador: } \$ 101 \text { per DALY averted }{ }^{27} \\
\text { Ghana: } \$ 11 \text { per DALY averted }{ }^{27} \\
\text { Inguinal hernia: US\$10-100 per DALY } \\
\text { averted }^{27} \\
\text { Repair with mosquito-net mesh: } \\
\text { US\$12.88 per DALY averted }{ }^{40}\end{array}$ & $\begin{array}{l}\text { US\$400 per patient }{ }^{27} \\
\text { Emergency C-section: US\$15-380 per DALY } \\
{\text { averted }{ }^{27}}^{\text {Emergency obstetric care in Bangladesh: } \$ 11} \\
\text { per DALY averted }{ }^{41}\end{array}$ \\
\hline DALY averted & $\begin{array}{l}\text { Estimated numberof } \\
\text { avertable DALYs } \\
\text { with scaling up } \\
\text { surgical care: } \\
5076572^{27}\end{array}$ & 7.42 per case ${ }^{36}$ & $\begin{array}{l}\text { Estimated number of avertable } \\
\text { DALYs with scaling up surgical } \\
\text { care: } 4207758^{27}\end{array}$ & $\begin{array}{l}\text { Estimated number of deaths and } \\
\text { DALYs averted per year that could } \\
\text { be prevented if basic surgical care } \\
\text { provided in LMIC: } \\
\text { Deaths: } 1042292 \\
\text { DALYs: } 52316946^{27}\end{array}$ & $\begin{array}{l}\text { Estimated number of deaths and } \\
\text { DALYs averted per year that could } \\
\text { be prevented if basic surgical care } \\
\text { provided in LMIC: } \\
\text { Deaths: } 14065 \\
\text { DALYs: } 325308^{27} \\
11 \text { DALYs per } 100000 \text { population }^{42}\end{array}$ & $\begin{array}{l}\text { Estimated number of deaths and DALY averted } \\
\text { per year that could be prevented if basic } \\
\text { surgical care provided in LMIC (obstructed } \\
\text { labor): Deaths: } 10882 \\
\text { DALYs: } 606833^{27} \\
\text { Estimated number of avertable DALYs w/ } \\
\text { scaling up surgical care (fistula): } 996553^{27}\end{array}$ \\
\hline
\end{tabular}


Henry et al

Table 3. Continued

Clubfoot

Cataracts

Injuries

Hernia

Fistula

Average cost-effectiveness

$\$ 15.44-96.04$ cost/ ratio of \$22.46 per DALY DALY averted ${ }^{9} \quad$ averted $^{36}$

ROI

Benefit-cost ratio of US\$120000 in regained

12 (specialized cleft lifetime earnings per child (or

clinic in India) ${ }^{43}$ net present value of \$13K per child treated $)^{35}$

cost/DALY averted \$32.78-\$223.00

\$5.06-\$106 cost/DALY averted ${ }^{9} \quad$ First level hospital in Bangladesh:

US\$11 per DALY averted ${ }^{41}$

First level hospital in Cambodia:

US\$78 per DALY averted ${ }^{38}$

Emergency C-section \$18-\$3,462 cost/DALY averted $^{9}$

C-section for obstructed labor: SSA: US\$73 per DALY averted

South-East Asia: US\$2,638 per DALY averted ${ }^{27}$ C-section services vary widely by country from C-section services vary widely by country from higher maternal morbidity risks to US\$3462

per DALY averted in other countries 27,34

Fistula surgery in Ethiopia - savings of US\$40 per DALY averted ${ }^{27}$

Analysis in India: combining cost savings of effective family planning with cost savings of

1.2 million children in LMICs ( $70 \%$ of cases) were to be treated by 2030, US\$1.5

billion in earning wound be generated ${ }^{35}$
Global economic impact of these Trauma is the leading cause of death treatable conditions has resulted in men and women ages 15-44, in a productivity loss of US\$19- the most economically productive 168 billion and 25 million DALYs ${ }^{27}$ population ${ }^{45}$
Annual combined economic loss due to disability from LF in India and SSA is estimated at US\$1.5-2 billion providing emergency obstetric care could = savings of US\$1.5B per year and reduction of maternal mortality by $75 \%{ }^{46}$

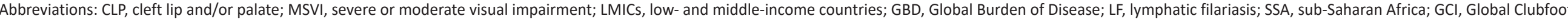
nitiative; RTI, road traffic accidents; NGO, non-governmental organization; ROI; return on investment; NSD, neglected surgical disease; DALY, disability-adjusted life-year.

* Total cost estimated from (estimated global backlog) (average cost per treatment).

* United Nations Population Fund (UNFPA) Campaign to End Fistula/World Health Organization (WHO)/Johns Hopkins University 2020 updated estimates, unpublished data.

a insufficient data. 
region but the commonalities will include: case detection at the community level and at birth (for congenital deformities) with subsequent formal referral channels, community door to door outreach by community health workers, advocacy and educational campaigns at all levels, training of the health workforce in screening, case detection, referral, and treatment. This is complemented by partnerships with the local government health department and a partner local collegiate society, NGO, or academic institution who not only works with local institutions and either reimburses cases done but also provides funding and training of the local health workforce in the abovementioned areas.

Several limitations deserve mention. First, specifying index conditions carry the danger of excluding other conditions that could also be addressed in this type of project; however, as a pilot initiative that seeks validation, a targeted approach renders the logistics around the eradication effort achievable even for an under-resourced country. Subsequent country-led expansion addressing endemic neglected surgical conditions can ensue. Second, disparate measurements of the various NSDs discussed currently exist, necessitating a unified global definition of NSDs centered around eliminating systemic neglect (eg, the mean age of diagnosis of an NSD or the minimum acceptable levels of treatment to prevent disability). This must align with existing initiatives (ie, UHC, eliminating neglected tropical diseases, NTDs) that governments can leverage existing resources to maximize impact. Third, defined surgical lists already exist (eg, Bellwether procedures, DCP3, Amsterdam Declaration on Essential Surgery $)^{47}$ and may presumably add to competing priorities; however, these surgical indices focus on the process of surgical delivery instead of outcomes, which can provide a more accurate picture of the surgical need in remote and underserved areas.

\footnotetext{
A Common Definition of Neglected Surgical Diseases Defining a subset of neglected surgical conditions that illustrates society's role and responsibility in addressing them provides a framework through the HRBA lens for its eventual eradication. Strategic guiding principles will be critical in ensuring that we avoid the common pitfalls described above while illustrating the pathway and rationale for adoption. The abovementioned propose a public health framework for surgically correctable conditions that can be identified at the primary care level and subsequently referred and treated at designated institutions with established local partnerships. The framework engages established local public health vehicles and systematizes the solution by targeting disease eradication while strengthening the health system. By providing a new model for disease elimination, the project seeks to create sustainable and resilient surgical infrastructure for the world's most vulnerable populations while simultaneously providing an incentive for governments to direct investments into strengthening their health systems. Addressing NSDs as a package has the potential to leverage economies of scale in resource-pooling and can represent a 'best buy' for governments. We therefore call for the adoption of a common definition for the six index surgical conditions
}

as NSDs to aid in collective implementation of eradication efforts through public health systems strengthening. We believe that this will pave the way for subsequent identification and treatment of other neglected surgical conditions. We will all be best served if we share a common definition of the issue in which we work and to which we encourage others to collaborate towards collective impact to achieve the vision of ending NSDs, achieving surgical integration within UHC, and thus attaining the Sustainable Development Goal vision of 'Leaving No One Behind' by 2030.

\section{Ethical issues}

Ethical approval was obtained from Mount Kenya University Ethics Review Committee (No. MKU/ERC/1167).

\section{Competing interests}

Authors declare that they have no competing interests.

\section{Authors' contributions}

Conception and design: JAH, OH, JB, DH, and RLM. Acquisition of data: ASV, $\mathrm{PM}, \mathrm{TF}, \mathrm{KM}, \mathrm{GS}$, and RO. Analysis and interpretation of data: ASV, JAH, LH, and $\mathrm{OH}$. Drafting of the manuscript: JH, ASV, OH, EA, GS, and RO. Critical revision of the manuscript for important intellectual content: $\mathrm{GS}, \mathrm{CL}, \mathrm{CM}, \mathrm{EA}$, $\mathrm{OH}$, and RL. Obtaining funding: JAH, OH, TF, KM, and PA. Administrative, technical, or material support: KM, TF, SK, EW, ASV, PM, CM, PJ, MN, LN, FA, NP, MLS, RL, EM, DO, AL, and ES. Supervision: PJ, LH, FA, TF, KM, and PM.

\section{Funding}

This work was supported by the Meru Government of Kenya, Odiongan Municipality of Romblon province, Philippines, and the Henry Family Advised Fund.

\section{Authors' affiliations}

${ }^{1}$ The Global Alliance for Surgical, Obstetric, Trauma, and Anesthesia Care (G4 Alliance), Chicago, IL, USA. International Collaboration for Essential Surgery (ICES), Boca Raton, FL, USA. ${ }^{3}$ Department of Surgery, Florida Atlantic University (FAU), Boca Raton, FL, USA. ${ }^{4}$ Baylor College of Medicine Division of Plastic Surgery, Texas Children's Hospital, Houston, TX, USA. ${ }^{5}$ Ministry of Health Kenya, Nairobi, Kenya. ${ }^{6}$ County Government of Meru County, Meru County, Kenya. ${ }^{7}$ Provincial Government of Odiongan, Odiongan, Philippines. ${ }^{8}$ Joint United Nations Programme on HIVIAIDS (UNAIDS), Geneva, Switzerland. ${ }^{9}$ Finders Keepers Technologies LLC, Boca Raton, FL, USA. ${ }^{10}$ University of Nairobi College of Health Sciences, Nairobi, Kenya. ${ }^{11}$ Mount Kenya University (MKU), Thika, Kenya. ${ }^{12}$ United Nations Population Fund (UNFPA), Nairobi, Kenya. ${ }^{13}$ Beyond Zero Secretariat, Kenya First Ladies' Office, Nairobi, Kenya. ${ }^{14}$ United Nations Population Fund (UNFPA), Campaign to End Fistula, New York City, NY, USA. ${ }^{15}$ International Federation of Gynecology and Obstetrics (FIGO), Vancouver, BC, Canada. ${ }^{16}$ University of Oxford, Oxford, UK. ${ }^{17} \mathrm{Global}$ Clubfoot Initiative (GCI), London, UK. ${ }^{18}$ Smile Train International, New York City, NY, USA. ${ }^{19}$ World Surgical Foundation (WSF) Philippines, Manila, Philippines. ${ }^{20}$ Orbis International, New York City, NY, USA. ${ }^{21}$ International Federation of Surgical Colleges (IFSC), London, UK. ${ }^{22}$ Child Family Health International Philippines, Manila, Philippines. ${ }^{23}$ Government of Trinidad and Tobago, Port of Spain, Trinidad and Tobago. ${ }^{24}$ Northwestern University Lurie Children's Hospital, Chicago, IL, USA. ${ }^{25}$ Mobile Surgery International, Oaxaca, Mexico. ${ }^{26}$ University of Washington Harborview Injury Prevention and Research Center, Seattle, WA, USA. ${ }^{27}$ College of Surgeons of East, Central, and Southern Africa (COSECSA), Arusha, Tanzania.

\section{References}

1. Groen RS, Samai M, Stewart KA, et al. Untreated surgical conditions in Sierra Leone: a cluster randomised, cross-sectional, countrywide survey. Lancet. 2012;380(9847):1082-1087. doi:10.1016/s01406736(12)61081-2

2. Petroze RT, Groen RS, Niyonkuru F, et al. Estimating operative disease prevalence in a low-income country: results of a nationwide population survey in Rwanda. Surgery. 2013;153(4):457-464. doi:10.1016/j.surg.2012.10.001

3. Varela C, Young S, Groen R, Banza L, Mkandawire NC, Viste A. 
Untreated surgical conditions in Malawi: a randomised cross-sectional nationwide household survey. Malawi Med J. 2017;29(3):231-236. doi:10.4314/mmj.v29i3.1

4. Mock CN, Donkor P, Gawande A, Jamison DT, Kruk ME, Debas HT. Essential surgery: key messages from Disease Control Priorities, 3rd edition. Lancet. 2015;385(9983):2209-2219. doi:10.1016/s01406736(15)60091-5

5. Ozgediz D, Riviello R. The "other" neglected diseases in global public health: surgical conditions in sub-Saharan Africa. PLoS Med. 2008;5(6):e121. doi:10.1371/journal.pmed.0050121

6. Maine RG, Linden AF, Riviello R, et al. Prevalence of untreated surgical conditions in rural Rwanda: a population-based crosssectional study in Burera district. JAMA Surg. 2017;152(12):e174013. doi:10.1001/jamasurg.2017.4013

7. Hagander L. Surgery for all: the right to heal. Lancet. $2014 ; 383(9932): 1877$.

8. Chirdan LB, Ameh EA. Untreated surgical conditions: time for global action. Lancet. 2012;380(9847):1040-1041. doi:10.1016/s01406736(12)61305-1

9. Grimes CE, Henry JA, Maraka J, Mkandawire NC, Cotton M. Costeffectiveness of surgery in low- and middle-income countries: a systematic review. World J Surg. 2014;38(1):252-263. doi:10.1007/ s00268-013-2243-y

10. Meara JG, Leather AJ, Hagander L, et al. Global surgery 2030: evidence and solutions for achieving health, welfare, and economic development. Int J Obstet Anesth. 2016;25:75-78. doi:10.1016/j. ijoa.2015.09.006

11. Biccard BM, Madiba TE, Kluyts HL, et al. Perioperative patient outcomes in the African Surgical Outcomes Study: a 7-day prospective observational cohort study. Lancet. 2018;391(10130):1589-1598. doi:10.1016/s0140-6736(18)30001-1

12. Citron I, Chokotho L, Lavy C. Prioritisation of surgery in the National Health Strategic Plans of Africa: a systematic review. World J Surg. 2016;40(4):779-783. doi:10.1007/s00268-015-3333-9

13. Ozgediz D, Langer M, Kisa P, Poenaru D. Pediatric surgery as an essential component of global child health. Semin Pediatr Surg. 2016; 25(1):3-9. doi:10.1053/j.sempedsurg.2015.09.002

14. Ng-Kamstra JS, Greenberg SLM, Abdullah F, et al. Global surgery 2030: a roadmap for high income country actors. BMJ Glob Health. 2016;1(1):e000011. doi:10.1136/bmjgh-2015-000011

15. Global, regional, and national incidence, prevalence, and years lived with disability for 354 diseases and injuries for 195 countries and territories, 1990-2017: a systematic analysis for the Global Burden of Disease Study 2017. Lancet. 2018;392(10159):1789-1858. doi:10.1016/s0140-6736(18)32279-7

16. Beard JH, Ohene-Yeboah M, Devries CR, Schecter WP. Hernia and hydrocele. In: Debas HT, Donkor P, Gawande A, Jamison DT, Kruk ME, Mock CN, eds. Essential Surgery: Disease Control Priorities. Third Edition (Volume 1). Washington, DC: The International Bank for Reconstruction and Development/The World Bank; 2015

17. Gutnik L, Yamey G, Riviello R, Meara JG, Dare AJ, Shrime MG. Financial contributions to global surgery: an analysis of 160 international charitable organizations. Springerplus. 2016;5(1):1558. doi:10.1186/s40064-016-3046-z

18. World Health Organization (WHO). Strengthening Emergency and Essential Surgical Care and Anaesthesia as a Component of Universal Health Coverage. http://apps.who.int/gb/ebwha/pdf_files/ WHA68/A68_R15-en.pdf?ua=1. Published 2015.

19. Haider A, Scott JW, Gause CD, et al. Development of a unifying target and consensus indicators for global surgical systems strengthening: proposed by the global alliance for surgery, obstetric, trauma, and anaesthesia care (the G4 alliance). World J Surg. 2017;41(10):24262434. doi:10.1007/s00268-017-4028-1

20. Gajewski J, Bijlmakers L, Brugha R. Global surgery - informing national strategies for scaling up surgery in sub-Saharan Africa. Int $J$ Health Policy Manag. 2018;7(6):481-484. doi:10.15171/ijhpm.2018.27

21. World Health Organization (WHO). Social determinants of health. WHO website. https://www.who.int/social_determinants/thecommission/finalreport/key_concepts/en/. Accessed December 16, 2019. Published 2019.

22. Brooks D, Douglas M, Aggarwal N, Prabhakaran S, Holden K, Mack D. Developing a framework for integrating health equity into the learning health system. Learn Health Syst. 2017;1(3). doi:10.1002/Irh2.10029

23. United Nations Development Programme (UNDP). Integrating Human Rights with Sustainable Human Development. New York: UNDP; 1998.

24. UN. Social Protection and Human Rights. https://socialprotectionhumanrights.org/. Published 2015. Accessed April 30, 2020.

25. American Cleft Palate-Craniofacial Association (ACPA). Parameters for Evaluation and Treatment of Patients with Cleft Lip/Palate or other Craniofacial Differences. Chapel Hill, NC: ACPA; 2018.

26. Digge V, Desai J, Das S. Expanded age indication for ponseti method for correction of congenital idiopathic talipes equinovarus: a systematic review. J Foot Ankle Surg. 2018;57(1):155-158. doi:10.1053/j.jfas.2017.08.015

27. Debas HT, Donkor P, Gawande A, Jamison DT, Kruk ME, Mock $\mathrm{CN}$, eds. Essential Surgery: Disease Control Priorities, Third Edition (Volume 1). Washington, DC: The International Bank for Reconstruction and Development/The World Bank; 2015.

28. World Health Organization (WHO). 10 Facts on Obstetric Fistula https://www.who.int/features/factfiles/obstetric_fistula/en/. Published 2018. Accessed April 2, 2019.

29. Farmer D, Sitkin N, Lofberg K, Donkor P, Ozgediz D. Surgical Interventions for Congenital Anomalies. In: Debas HT, Donkor P, Gawande A, Jamison DT, Kruk ME, Mock CN, eds. Essential Surgery: Disease Control Priorities, Third Edition (Volume 1). Washington, DC: The International Bank for Reconstruction and Development/The World Bank; 2015

30. Global Clubfoot Initiative. Global Clubfoot Report 2013. http:// globalclubfoot.com/wp-content/uploads/downloads/2015/07/Globaldata-report-2013-WEBSITE-DOWNLOAD.pdf. Accessed April 2, 2019.

31. World Health Organization (WHO). Blindness and Vision Impairment Prevention. https://www.who.int/blindness/causes/priority/en/index1. html. Accessed March 13, 2019.

32. Bourne R, Resnikoff S, Ackland P. GBVI-Global Cause Estimates. Vision Atlas; 2019. http://atlas.iapb.org/global-burden-visionimpairment/gbvi-global-cause-estimates/. Accessed March 11, 2019.

33. Flaxman SR, Bourne RRA, Resnikoff S, etal. Global causes of blindness and distance vision impairment 1990-2020: a systematic review and meta-analysis. Lancet Glob Health. 2017;5(12):e1221-e1234. doi:10.1016/s2214-109x(17)30393-5

34. Alkire BC, Vincent JR, Meara JG. Benefit-cost analysis for selected surgical interventions in low-and middle-income countries. In: Debas HT, Donkor P, Gawande A, Jamison DT, Kruk ME, Mock CN, eds. Essential Surgery: Disease Control Priorities, Third Edition (Volume 1). Washington, DC: The International Bank for Reconstruction and Development/The World Bank; 2015.

35. Global Clubfoot Initiative. Run Free 2030: A Global Strategy for Clubfoot Disability. https://globalclubfoot.com/runfree2030/. Accessed January 2019. Published 2017.

36. Grimes CE, Holmer H, Maraka J, Ayana B, Hansen L, Lavy CBD. Cost-effectiveness of club-foot treatment in low-income and middleincome countries by the Ponseti method. BMJ Glob Health. 2016; 1(1):e000023. doi:10.1136/bmjgh-2015-000023

37. Gosselin RA, Maldonado A, Elder G. Comparative cost-effectiveness analysis of two MSF surgical trauma centers. World J Surg. 2010;34(3):415-419. doi:10.1007/s00268-009-0230-0

38. Gosselin RA, Heitto M. Cost-effectiveness of a district trauma hospital in Battambang, Cambodia. World J Surg. 2008;32(11):2450-2453. doi:10.1007/s00268-008-9708-4

39. Ahachi CN, Fadeyibi IO, Abikoye FO, Chira MK, Ugburo AO, Ademiluyi SA. The direct hospitalization cost of care for acute burns in Lagos, Nigeria: a one-year prospective study. Ann Burns Fire Disasters. 2011;24(2):94-101.

40. Shillcutt SD, Clarke MG, Kingsnorth AN. Cost-effectiveness of groin hernia surgery in the Western Region of Ghana. Arch Surg. 2010; 145(10):954-961. doi:10.1001/archsurg.2010.208

41. McCord C, Chowdhury Q. A cost effective small hospital in Bangladesh: what it can mean for emergency obstetric care. Int J Gynaecol Obstet. 2003;81(1):83-92. doi:10.1016/s0020-7292(03)00072-9

42. Hotez PJ, Alvarado M, Basáñez MG, et al. The global burden of disease study 2010: interpretation and implications for the neglected tropical diseases. PLoS Negl Trop Dis. 2014;8(7):e2865. doi:10.1371/ 
journal.pntd.0002865

43. Alkire B, Hughes CD, Nash K, Vincent JR, Meara JG. Potential economic benefit of cleft lip and palate repair in sub-Saharan Africa. World J Surg. 2011;35(6):1194-1201. doi:10.1007/s00268-011-10551

44. Massenburg BB, Jenny HE, Saluja S, Meara JG, Shrime MG, Alonso N. Barriers to cleft lip and palate repair around the world. $J$ Craniofac Surg. 2016;27(7):1741-1745. doi:10.1097/scs.0000000000003038

45. World Health Organization (WHO). The Injury Chart Book: A Graphical Overview of the Global Burden of Injuries. Geneva, Switzerland:
WHO; 2002.

46. Goldie SJ, Sweet S, Carvalho N, Natchu UC, Hu D. Alternative strategies to reduce maternal mortality in India: a cost-effectiveness analysis. PLoS Med. 2010;7(4):e1000264. doi:10.1371/journal. pmed. 1000264

47. Henry JA, Price R. The transforming power of high-quality surgical care: surgery's role in improving public health. In: Park A, Price R, eds. Global Surgery: The Essentials. Cham: Springer; 2017:13-34. doi:10.1007/978-3-319-49482-1_2 